\title{
Managing patients with stable respiratory disease planning air travel: a primary care summary of the British Thoracic Society recommendations
}

\section{* Lynn K Josephs', Robina K Coker², Mike Thomas ${ }^{1}$, on behalf of the BTS Air Travel Working Group}

1 Primary Care Research, Aldermoor Health Centre, University of Southampton, Southampton, UK

2 Department of Respiratory Medicine, Hammersmith Hospital, du Cane Road, London, UK

Received 28th February 2013; revised 11th April 2013; accepted 14th April 2013; online 29th May 2013

\begin{abstract}
Air travel poses medical challenges to passengers with respiratory disease, principally because of exposure to a hypobaric environment. In 2002 the British Thoracic Society published recommendations for adults and children with respiratory disease planning air travel, with a web update in 2004. New full recommendations and a summary were published in 2011, containing key recommendations for the assessment of high-risk patients and identification of those likely to require in-flight supplemental oxygen. This paper highlights the aspects of particular relevance to primary care practitioners with the following key points: (1) At cabin altitudes of 8000 feet (the usual upper limit of in-flight cabin pressure, equivalent to 0.75 atmospheres) the partial pressure of oxygen falls to the equivalent of breathing $15.1 \%$ oxygen at sea level. Arterial oxygen tension falls in all passengers; in patients with respiratory disease, altitude may worsen preexisting hypoxaemia. (2) Altitude exposure also influences the volume of any air in cavities, where pressure $\mathrm{x}$ volume remain constant (Boyle's law), so that a pneumothorax or closed lung bulla will expand and may cause respiratory distress. Similarly, barotrauma may affect the middle ear or sinuses if these cavities fail to equilibrate. (3) Patients with respiratory disease require clinical assessment and advice before air travel to: (a) optimise usual care; (b) consider contraindications to travel and possible need for in-flight oxygen; (c) consider the need for secondary care referral for further assessment; (d) discuss the risk of venous thromboembolism; and (e) discuss forward planning for the journey.

() 2013 Primary Care Respiratory Society UK. All rights reserved.

LK Josephs et al. Prim Care Respir J 2013; 22(2): 234-238

http://dx.doi.org/10.4104/pcrj.2013.00046
\end{abstract}

Keyw ords BTS guideline, summary, air travel, respiratory diseases, primary care

\section{Background}

Many patients with chronic respiratory disease, even those receiving long-term oxygen therapy (LTOT), wish to travel by air and therefore seek medical advice. In addition, travellers who become ill abroad are often keen to fly home. How best to assess and advise such passengers is an increasingly common situation faced by general practitioners (GPs), complicated by increasing co-morbidity in older travellers. With long haul flights, passengers are exposed to cabin altitudes of up to 8000 feet for many hours. Long flights are associated with increased risks of in-flight medical incidents related to hypoxia or to prolonged immobility. No resting measures of lung function (including oxygen saturations at sea level and forced expiratory volume in one second, $\mathrm{FEV}_{1}$ ) reliably predict hypoxaemia or complications. ${ }^{1-5}$

In 2002 the British Thoracic Society (BTS) published recommendations for adults and children with respiratory disease planning air travel, ${ }^{6}$ with a web update in 2004. ${ }^{7}$ New full recommendations ${ }^{8}$ and a summary ${ }^{9}$ were published in 2011 , containing key recommendations for the assessment of high-risk patients and identification of those likely to require in-flight supplemental oxygen. The BTS recommendations represent a consensus of expert opinion based on the available evidence, provide an up-to-date literature review, and offer practical evidence-graded advice. This paper highlights those aspects of the BTS air travel recommendations which are of particular relevance to primary care practitioners.

It is difficult to determine the size of the problem as there are no established methods of quantifying in-flight medical emergencies. ${ }^{10}$ In one US study, respiratory events represented $7 \%$ of 754 incidents ${ }^{11}$ while, in other studies, respiratory events accounted for 9-11\% of incidents. ${ }^{12,13}$

\footnotetext{
* Corresponding author: Dr Lynn K Josephs, Primary Care Research, Aldermoor Health Centre, University of Southampton, Aldermoor Close, Southampton SO16 5ST, UK. E-mail: L.Josephs@soton.ac.uk
} 


\section{Pre-flight discussion}

Many patients with complex or severe respiratory problems will be under the care of specialist teams but may still present for advice from primary care, as may others with milder disease. The following points should be considered:

- Patients may need referral for a hypoxic challenge test (HCT), simulating oxygen tensions encountered in flight to assess the need for in-flight oxygen.

- Clarification that the patient takes responsibility for any decision to fly, but that the airline can refuse carriage if the patient's safety is in doubt.

- Patients using continuous positive airways pressure or LTOT may use equipment in flight but only by prior arrangement with airlines. Supplemental oxygen may be provided by the aircraft systems or by small cylinders by prior arrangement. Patients requiring oxygen should be reminded to make arrangements for oxygen provision at their destinations.

- There needs to be discussion about holiday insurance, the cost of emergency treatment, and any repatriation if required.

- Patients should carry appropriate medication in their hand luggage and consideration should be given to the need for emergency medical supplies such as antibiotics or prednisolone.

- Patients may need a GP's letter explaining their medical needs to airlines or immigration authorities.

- A frequent traveller's medical card (FREM EC) may be useful for patients who fly regularly.

- General advice to keep well hydrated, avoid alcohol, and keep mobile.

- Patients can be directed to additional sources of information (see Box 1)

\section{Box 1. Information resources for patients}

British Lung Foundation information on travel:

http://www.blf.org.uk/

ELF air travel database (detailed advice airlines and oxygen): http://www.european-lung-foundation.org/

BTS patient information leaflet on air travel: http://www.brit-thoracic.org.uk/

\section{Pre-flight assessment for adults}

Consideration should be given to the patient's intended destination and flight duration, their previous flight experience, and the time since the last exacerbation of their respiratory disease. Box 2 lists

\section{Box 2. Recommendations for adults}

Contraindications to travel:

- Infectious tuberculosis

- Ongoing pneumothorax with persistent air leak

- Major haemoptysis

- Patients on LTOT whose usual oxygen requirements exceed $4 \mathrm{~L} / \mathrm{min}$ at sea level (because commercial airlines are unable to deliver double this rate, which would be the usual recommendation at altitude).

High-risk patients requiring further evaluation (see Figure 1):

- Patients with previous significant respiratory symptoms associated with air travel.

- Severe chronic obstructive pulmonary disease ( $\mathrm{FEV}_{1}<30 \%$ predicted), bullous lung disease, difficult-tocontrol asthma, cystic fibrosis, or pulmonary tuberculosis.

- Severe restrictive disease (vital capacity $<1 \mathrm{~L}$ ) including interstitial lung disease, chest wall and respiratory muscle disease, especially if associated with hypoxaemia and/or hypercapnia.

- Co-morbidity with conditions made worse by hypoxaemia (e.g. cerebrovascular disease, cardiac disease, pulmonary hypertension).

- Recent pneumothorax or within six w eeks of an acute respiratory illness.

- Risk of, or previous history of, venous thromboembolism.

- Pre-existing requirement for oxygen, continuous positive airways pressure or ventilator support.

contraindications to air travel and indicates high-risk patient groups requiring further evaluation.

The algorithm in Figure 1 outlines recommendations for managing these patients. In particular, it highlights the need to refer for further assessment any patient not receiving LTOT whose resting oxygen saturation is $<95 \%$ breathing air.

Figure 1. Algorithm for managing adult passengers with stable respiratory disease planning air travel. ${ }^{9}$ LTOT=longterm oxygen therapy, VTE=venous thromboembolism, $\mathrm{PaO}_{2}=$ arterial oxygen tension, $\mathrm{SpO}_{2}=0$ xygen saturation

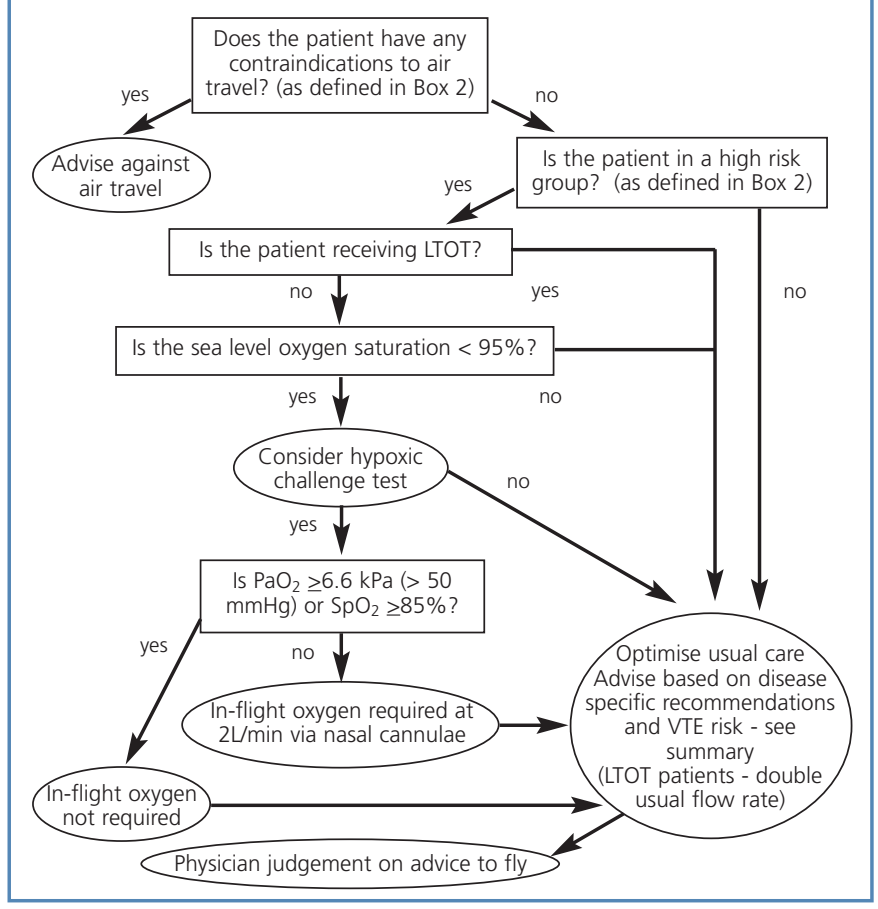




\section{Hypoxic challenge testing (HCT)}

The purpose of HCT is to determine the need for in-flight oxygen by exposing the patient to the hypoxia experienced at a cabin altitude of 8000 feet and measuring hypoxaemia. It is not a 'fitness to fly' test. The test is performed in a specialist lung function unit. The maximum cabin altitude of 8000 feet can be simulated using a mixture containing $15 \%$ oxygen in nitrogen, which the patient is required to breathe for 20 mins. $^{14,15} \mathrm{~A}$ full simulation can only be performed in a hypobaric chamber, but this is rarely required. Interpretation of the results of HCT is shown in Box 3.

HCT should be considered in patients in a risk group (Box 2) who are not already receiving LTOT at sea level and whose oxygen saturation $\left(\mathrm{SpO}_{2}\right)$ at rest is $<95 \%$ breathing air. Pulse oximetry should permit GPs to assess resting oxygen saturation and determine the need for referral.

Patients already receiving LTOT at sea level should be prescribed in-flight oxygen at double their usual flow rate while at cruising altitude; they do not require HCT.

Although HCT is considered to be the clinical 'gold standard' for predicting in-flight hypoxaemia, it is time-consuming and is not universally available. Several prediction equations have been derived to estimate in-flight arterial oxygen tension $\left(\mathrm{PaO}_{2}\right)$ or $\mathrm{SpO}_{2}$ from sea level measurements and are detailed in the latest BTS recommendations. ${ }^{8}$ A recent Norwegian study ${ }^{16}$ has described evaluation in patients with chronic obstructive pulmonary disease (COPD) using pulse oximetry at rest and after a 6 minute walk test, and reported good concordance with HCT.

Box 3. Interpretation of results of hypoxic challenge test

If $\mathrm{PaO}_{2} \geq 6.6 \mathrm{kPa}(>50 \mathrm{mmHg})$ or $\mathrm{SpO}_{2} \geq 85 \%$ : in-flight oxygen is not required.

If $\mathrm{PaO}_{2}<6.6 \mathrm{kPa}\left(<50 \mathrm{mmHg}\right.$ ) or $\mathrm{SpO}_{2}<85 \%$ : in-flight oxygen is required at a rate of $2 \mathrm{~L} / \mathrm{min}$ via nasal cannulae.

\section{Recommendations for infants and children}

Young children show a less predictable response to hypoxic environments with an increased risk of symptomatic hypoxia in very young and preterm infants. ${ }^{17}$ For infants born at term, it is prudent to delay flying for one week after birth term (corrected gestational age 40 weeks) to ensure they are healthy. Infants born prematurely (<37 weeks) do not require HCT because it is unreliable in this group. ${ }^{18}$ If they must fly, they should have in-flight oxygen available to be delivered at $1-2 \mathrm{~L} / \mathrm{min}$ if the baby shows any sign of respiratory distress.

Older ex-preterm infants with a history of significant respiratory tract infection should delay flying for six months after their estimated date of delivery owing to an increased risk of apnoea. ${ }^{19}$ Children aged $<1$ year with a history of chronic respiratory problems should be referred for specialist assessment and HCT. Similarly, older children with more severe chronic respiratory disease should be referred for specialist assessment and HCT. Recommendations for children are summarised in Box 4.
Box 4. Recommendations in infants and older children

1. If the child is receiving LTOT at sea level: double usual flow rate while at cruising altitude.

2. If the child has required LTOT within the previous six months: refer for $\mathrm{HCT}^{20}$

3. Older children with chronic lung disease including cystic fibrosis: if $\mathrm{FEV}_{1}<50 \%$ predicted, refer for $\mathrm{HCT}$; in-flight oxygen will be needed if test is positive. ${ }^{21,22}$

\section{Disease-specific recommendations}

\section{Asthma}

Commercial flights do not usually pose undue problems for people with asthma, although it is prudent for asthma therapy to be optimised prior to travel and for inhaled medication to be carried in hand luggage. The commonest problem is of a minor acute exacerbation occurring in passengers without access to their rescue bronchodilator. Patients with severe or brittle asthma should consult their specialist beforehand and should carry their usual medication, spacer, and emergency prednisolone in their hand luggage.

\section{Chronic obstructive pulmonary disease (COPD)}

Patients with COPD are potentially at risk from altitude-induced hypoxaemia and from expansion of gases within closed body cavities (bullae and pneumothoraces). However, the frequency of severe air travel-related adverse events is low in these patients, who generally tolerate moderate hypoxaemia well. Patients with severe COPD ( $\mathrm{FEV}_{1}<30 \%$ predicted) should consult their specialist beforehand and should carry their usual medication, spacer, and emergency prednisolone in their hand luggage. Pulse oximetry can be performed in primary care to identify significant hypoxaemia and such patients should be referred for HCT.

\section{Pneumothorax or recent thoracic surgery}

Patients with a pneumothorax should not fly. After a documented pneumothorax, a pre-flight chest $x$-ray should be arranged to ensure resolution; a further delay of 7 days (spontaneous pneumothorax) or 14 days (traumatic pneumothorax) is recommended. In patients with pre-existing lung disease, flying does not seem to make a pneumothorax more likely. ${ }^{722}$ Similar recommendations apply to those who have recently undergone thoracic surgery, in whom a recent chest $x$-ray is required. Recurrent pneumothorax is very unlikely following pleural surgery; non-surgical pleurodesis is less effective.

\section{Interstitial lung disease (ILD)}

Patients with significant interstitial lung disease (ILD) need specialist assessment and consideration of HCT prior to travel and may need supplemental oxygen in-flight and if staying at high altitude destinations. Emergency supplies of antibiotics and prednisolone may be advisable, with advice on managing steroid dose during intercurrent illness.

\section{Sinus and middle ear disease}

Risk factors for sinus or middle ear barotrauma include mucosal oedema, current bacterial infection, thick mucin, nasal polyps, and tumours. Failure of sinus and ear cavities to equilibrate usually 
causes problems on descent. Oral and topical decongestants before travel and descent are recommended for at-risk adults.

Passengers who do develop sinus barotrauma should be given topical and oral decongestants. Analgesics and oral steroids may be considered; antibiotics are advised if infection is the likely trigger, and antihistamines if allergy is suspected. Barotrauma should have resolved before flying again, which may take 1-6 weeks.

\section{Viral upper respiratory tract infections (URTI)}

Although the remit of this paper was to extract key points from the BTS recommendations for patients with significant respiratory disease, patients in primary care commonly seek advice about flying with a 'cold'. In this situation, Eustachian tube dysfunction may cause ear pain and risk of middle ear barotrauma, especially on descent. In adults and children, topical decongestants may aid equalisation of middle ear pressures when used before travel and before descent. In addition, oral decongestants taken before travel may be helpful in adults.

\section{Pneumonia}

Following pneumonia, patients should be afebrile and clinically stable; persisting significant hypoxia is a contraindication. Patients should only travel when infection has been adequately treated to minimise transmission of infection. ${ }^{23}$

\section{Cancer}

Many patients with cancer will wish to travel by air for a variety of reasons, and this should be possible in most cases. The patient should be as stable as possible following any treatment for cancer or its complications. Severe or symptomatic anaemia and metabolic disturbances should be corrected, and pleural effusions drained prior to travel. A doctor's letter will be required for patients taking controlled drugs, and the patient should consult the statutory governmental authorities about local controlled drug importation rules. Patients with recent major haemoptysis should not fly.

\section{Hyperventilation and dysfunctional breathing}

Acute anxiety and panic are not infrequent medical emergencies in air travel, and differentiation between panic-associated hyperventilation and a cardiorespiratory crisis can be difficult for air staff. For patients with a history of dysfunctional breathing or panic, appropriate psychological or psychiatric assessment is advisable. Breathing modification exercises and/or medication can be beneficial and should be considered before travel. Re-breathing techniques may be used on board for acute hyperventilation, and short-term use of rapidly acting anxiolytics may be helpful.

\section{Obstructive sleep apnoea}

Obstructive sleep apnoea is not a contraindication to air travel, but a doctor's letter is required outlining the diagnosis and the necessary equipment which will need to be taken as hand luggage. A useful fact sheet is available at http://www.sleepapnea.org/. Portable continuous positive airways pressure devices are available for travellers. The device used must be able to function on board (using dry cell batteries) and at the patient's destination. Liaison with the airline before the flight is needed.

\section{Cardiac co-morbidity}

Cardiac and pulmonary conditions frequently co-exist, and significant falls in oxygenation on commercial flights may worsen cardiac disease. Hypoxia induces pulmonary vasoconstriction which may increase pulmonary artery pressure in patients with pulmonary hypertension. Hypoxaemia induces systemic vasodilation, reducing systemic vascular resistance, but atherosclerotic coronary arteries may constrict in response to sympathetic activation. ${ }^{24,25}$ Clinically evident myocardial ischaemia is unlikely to develop at commercial aircraft pressures, ${ }^{26}$ and most passengers will not experience a change in threshold for ischaemic symptoms. The British Cardiac Society has published recommendations for patients with cardiac disease. ${ }^{27}$ However, as respiratory and cardiac conditions frequently co-exist, respiratory physicians are often consulted about cardiac disease and the BTS has therefore retained a section on cardiac conditions in their latest recommendations. They advise particular caution in patients with co-existing disease.

Patients with mild and stable angina should be able to fly safely. Those with Canadian Cardiovascular Society (CCS) functional class IV angina (chest pain at rest or a recent change in symptoms and/or medication) should defer travel until stable. Patients with New York Heart Association (NYHA) functional class IV heart failure (severe limitation with symptoms at rest) should not fly unless essential. If air travel cannot be avoided, in-flight oxygen is required. Specialist advice should be sought for patients with pulmonary hypertension. Pulse oximetry may be helpful in identifying those with hypoxaemia.

\section{Venous thromboembolism (VTE) prevention for flights more than $8 \mathrm{hrs}$ or multiple shorter flights over a short period}

GPs are frequently asked for advice on the prevention of venous thromboembolism (VTE) in air travel. There is no evidence to support aspirin prophylaxis. There is evidence of reduced risk if patients occupy an aisle seat with greater leg room. Patients can be advised according to risk:

- Low VTE risk: all patients not in categories below:

- Avoid excess alcohol and caffeine-containing drinks, remain mobile and exercise during the flight.

- Moderate risk for VTE: family history, past history of VTE with identifiable cause, thrombophilia, pulmonary arteriovenous malformations (PAVM ), obesity (body mass index $>30 \mathrm{~kg} / \mathrm{m}^{2}$ ), height $>1.9 \mathrm{~m}$ or $<1.6 \mathrm{~m}$, significant medical illness in previous six weeks, cardiac disease, immobility, pregnancy or oestrogen therapy (hormone replacement therapy or combined oral contraceptive pill) and postnatal (within two weeks of delivery)

- In addition to the above advice, wear below-knee compression stockings, avoid sedatives, and avoid sleeping for prolonged periods in abnormal positions (stockings may increase risk of superficial thrombophlebitis in patients with varicose veins).

- High risk for VTE: past history of idiopathic VTE (or patients with PAVM with a history of previous VTE or embolic stroke), within six weeks of major surgery or trauma, in patients with active malignancy

- In addition to the above advice, consider a pre-flight 
prophylactic dose of low molecular weight heparin or formal anticoagulation (INR 2-3).

- Patients who have had a VTE should not fly for four weeks or until the proximal deep vein thrombosis has been treated and symptoms resolved.

\section{Conclusions}

This summary of the BTS Air Travel Working Group provides guidance for primary care professionals when advising and assessing patients with respiratory disease who are contemplating air travel. In particular, it considers when to refer patients to secondary care for further assessment, including HCT which reliably identifies patients needing supplementary oxygen. ${ }^{28}$

\section{Handling editor Hilary Pinnock}

Acknowledgements We would like to thank all the members of the BTS Air Travel Working Group (S Ahmedzai, I M Balfour-Lynn, T Bewick, R Buchdahl, R K Coker (chair), A R Cummin, D P Gradwell, L Howard, J A Innes, A O C Johnson, E Lim, Wei Shen Lim, K P McKinlay, M R Partridge, M Popplestone, A Pozniak, A Robson, C L Shovlin, D Shrikrishna, A Simonds, P Tait, M Thomas) and the BTS Standards of Care Committee. We also thank Dinesh Shrikrishna for use of the algorithm in Figure 1 .

Conflicts of interest The authors declare that they have no conflicts of interest in relation to this article. MT is an Associate editor of the $P C R J$, but was not involved in the editorial review of, nor the decision to publish, this article. LKJ and RKC have no conflicts of interest in relation to this article.

Contributorship $L J$ wrote the first draft of this manuscript. All authors contributed to revisions and approved the final manuscript.

Funding The authors received no external funding for this work.

\section{References}

1. Akero A, Christensen CC, Edvardsen A, Ryg M, Skjonsberg OH. Pulse oximetry in the preflight evaluation of patients with chronic obstructive pulmonary disease. Aviat Space Environ Med 2008;79(5):518-24.

http://dx.doi.org/10.3357/ASEM .2120.2008

2. Christensen CC, Ryg M, Refvem OK, Skjonsberg OH. Development of severe hypoxaemia in chronic obstructive pulmonary disease patients at $2,438 \mathrm{~m}$ $(8,000 \mathrm{ft})$ altitude. Eur Respir J 2000;15(4):635-9. http://dx.doi.org/10.1183/09031936.00.15463500

3. Coker RK, Shiner RJ, Partridge MR. Is air travel safe for those with lung disease? Eur Respir J 2007;30(6):1057-63. http://dx.doi.org/10.1183/09031936.00024707

4. Robson AG, Hartung TK, Innes JA. Laboratory assessment of fitness to fly in patients with lung disease: a practical approach. Eur Respir J 2000;16(2):21419. http://dx.doi.org/10.1034/j.1399-3003.2000.16b06.x

5. Schwartz JS, Bencowitz HZ, Moser KM. Air travel hypoxemia with chronic obstructive pulmonary disease. Ann Intern Med 1984;100(4):473-7. http://dx.doi.org/10.7326/0003-4819-100-4-473

6. British Thoracic Society Standards of Care Committee, Air Travel Working Party. Managing passengers with respiratory disease planning air travel: British Thoracic Society recommendations. Thorax 2002;57:289-304. http://dx.doi.org/10.1136/thorax.57.4.289

7. British Thoracic Society Standards of Care Committee, Air Travel Working Party. Managing passengers with respiratory disease planning air travel: British Thoracic Society recommendations (web-based update), 2004. http://www.brit-thoracic.org.uk/guidelines/air-travel-guideline

8. Ahmedzai S, Balfour-Lynn IM, Bewick T, et al. Managing passengers with stable respiratory disease planning air travel: British Thoracic Society recommendations. Thorax 2011;66(Suppl 1):i1-i30. http://dx.doi.org/10.1136/thoraxjnl-2011-200295

9. Shrikrishna D, Coker RK. Managing passengers with stable respiratory disease planning air travel: British Thoracic Society recommendations. Thorax 2011;66(9):831-3. http://dx.doi.org/10.1136/thoraxjnl-2011-200694

10. Sand M, Bechara FG, Sand D, Mann B. Surgical and medical emergencies on board European aircraft: a retrospective study of 10189 cases. Crit Care 2009;13(1):R3. http://dx.doi.org/10.1186/cc7690

11. Golan Y, Onn A, Villa Y, et al. Asthma in adventure travelers: a prospective study evaluating the occurrence and risk factors for acute exacerbations. Arch Intern Med 2002;162(21):2421-6. http://dx.doi.org/10.1001/archinte.162.21.2421

12. Delaune EF, Lucas RH, Illig P. In-flight medical events and aircraft diversions: one airline's experience. Aviat Space Environ Med 2003;74(1):62-8.

13. Cummins RO, Schubach JA. Frequency and types of medical emergencies among commercial air travelers. JAMA 1989;261(9):1295-9. http://dx.doi.org/10.1001/jama.1989.03420090059031

14. Dillard TA, Moores LK, Bilello KL, Phillips YY. The preflight evaluation: a comparison of the hypoxia inhalation test with hypobaric exposure. Chest 1995;107(2):352-7. http://dx.doi.org/10.1378/chest.107.2.352

15. Gong H Jr. Tashkin DP, Lee EY, Simmons MS. Hypoxia-altitude simulation test. Evaluation of patients with chronic airway obstruction. Am Rev Respir Dis 1984;130(6):980-6.

16. Edvardsen A, Akero A, Christensen CC, Ryg M, Skjonsberg $\mathrm{OH}$. Air travel and chronic obstructive pulmonary disease: a new algorithm for pre-flight evaluation. Thorax 2012;67(11):964-9.

http://dx.doi.org/10.1136/thoraxjnl-2012-201855

17. Bossley C, Balfour-Lynn IM. Taking young children on aeroplanes: what are the risks? Arch Dis Child 2008;93(6):528-33. http://dx.doi.org/10.1136/adc.2007.122952

18. Resnick SM, Hall GL, Simmer KN, Stick SM, Sharp MJ. The hypoxia challenge test does not accurately predict hypoxia in flight in ex-preterm neonates. Chest 2008;133(5):1161-6. http://dx. doi.org/10.1378/chest.07-2375

19. Letsky EA. Anaemia in the newborn. Textbook of Neonatology. 3rd edn. Edinburgh and London: Churchill Livingstone, 1999; 3:806-33.

20. Balfour-Lynn IM, Field DJ, Gringras P, et al. BTS guidelines for home oxygen in children. Thorax 2009;64(Suppl 2):ii1-ii26. http://dx.doi.org/10.1136/thx.2009.116020

21. Buchdahl RM, Babiker A, Bush A, Cramer D. Predicting hypoxaemia during flights in children with cystic fibrosis. Thorax 2001;56(11):877-9. http://dx.doi.org/10.1136/thorax.56.11.877

22. Oades PJ, Buchdhal RM, Bush A. Predictions of hypoxaemia at high altitude in children with cystic fibrosis. BMJ 1994;308(6920):15-18. http://dx.doi.org/10.1136/bmj.308.6920.15

23. Aerospace Medical Association. Medical guidelines for airline travel, 2nd ed. Aviat Space Environ Med 2003;74(5 Suppl):A1-19.

24. Vita JA, Keaney Jr JF. Exercise-toning up the endothelium? N Engl J Med 2000;342(7):503-5. http://dx.doi.org/10.1056/NEJM 200002173420710

25. Wyss CA, Koepfli P, Fretz G, Seebauer M, Schirlo C, Kaufmann PA. Influence of altitude exposure on coronary flow reserve. Circulation 2003;108(10):1202-07. http://dx.doi.org/10.1161/01.CIR.0000087432.63671.2E

26. Bartsch P, Gibbs JS. Effect of altitude on the heart and the lungs. Circulation 2007; 116(19):2191-202. http://dx.doi.org/10.1161/CIRCULATIONAHA.106.650796

27. Smith $D$, Toff $W$, Joy $M$, et al. Fitness to fly for passengers with cardiovascular disease. Heart 2010;96(Suppl 2):ii1-ii16. http://dx.doi.org/10.1136/hrt.2010.203091

28. Akero A, Edvardsen A, Christensen CC, Owe JO, Ryg M, Skjonsberg OH. COPD and air travel: oxygen supplementation during air travel oxygen equipment and preflight titration of supplemental oxygen. Chest 2011;140(1):84-90. http://dx.doi.org/10.1378/chest.10-0965

\section{Available online at http://w w w.thepcrj.org}

